\title{
Anti-GAD antibodies in Chinese patients with youth and adult-onset IDDM and NIDDM
}

\author{
A.C. Thai ${ }^{1}$, W.Y. Ng ${ }^{1}$, K.Y. Loke ${ }^{2}$, W.R.W. Lee ${ }^{3}$, K. F. Lui ${ }^{1}$, J.S. Cheah ${ }^{1}$ \\ ${ }^{1}$ Department of Medicine, National University of Singapore, Republic of Singapore \\ ${ }^{2}$ Department of Paediatrics, National University of Singapore, Republic of Singapore \\ ${ }^{3}$ Department of Paediatrics, Singapore General Hospital, Republic of Singapore
}

Summary An autoimmune basis for the pathogenesis of insulin-dependent diabetes mellitus (IDDM) is supported by the frequent presence of autoantibodies - islet cell antibodies (ICAs) and GAD antibodies (GADab). However, in Chinese patients with clinical IDDM, a low prevalence of ICAs was observed. In non-insulin-dependent diabetic (NIDDM) patients, it has been suggested that the presence of GADab may identify a subset of latent autoimmune diabetes in adults (LADA). We determined the frequency of GADab in a large group of 134 IDDM and 168 NIDDM Chinese patients, and assessed the relation with ICAs status. Results showed that 39.6\% IDDM and $16.1 \%$ NIDDM patients had GADab, and $20.1 \%$ and $4.8 \%$, respectively had detectable ICAs. Frequency of GADab positivity was not influenced by whether the patients had youth or adult-onset
IDDM or NIDDM, or by duration of diabetes. NIDDM patients seropositive for GADab shared similar clinical characteristics and fasting C-peptide levels with those who were GADab negative. Presence of GADab therefore did not serve to identify a subgroup of patients with latent or slow-onset IDDM. Half $(53 \%)$ of our IDDM patients had neither GADab nor ICAs. The reason for this observation is unclear. One theory is that other autoantigens yet to be identified may be contributory. Alternatively, in the Chinese, autoimmunity may not be the major factor in the pathogenesis of IDDM. [Diabetologia (1997) 40: $1425-1430$ ]

Keywords GAD antibodies, islet cell antibodies, IDDM, NIDDM, Chinese.
Anti-glutamic acid decarboxylase antibodies (GADab) previously known as $64 \mathrm{kDa}$ antibodies were found to be present in the majority of new-onset insulin-dependent diabetic (IDDM) patients and those at risk of the disease [1-4]. In non-insulin-dependent diabetic (NIDDM) patients, the presence of GADab has led to the suggestion that these patients are perhaps a subset with latent IDDM, or LADA (latent autoimmune diabetes in adults) [5]. It has been estimated that $5-9 \%$ of NIDDM patients are LADA

Received: 11 March 1997 and in revised form: 13 May 1997

Corresponding author: Dr A.C. Thai, Department of Medicine, National University Hospital, Lower Kent Ridge Road, Singapore 119074, Republic of Singapore

Abbreviations: GADab, GAD antibodies; ICAs, islet cell antibodies; LADA, latent autoimmune diabetes in adults. subjects with GADab [6, 7]. Such patients also clinically resemble the classical IDDM patient, including being non-obese, insulin-requiring, with a history of ketoacidosis and low C-peptide levels.

In the Chinese, patients with IDDM had a low prevalence of islet cell antibodies (ICAs) and cellular markers of autoimmune activation. Compared to Caucasians, only a third $(30.6 \%)$ of Chinese patients with recent-onset IDDM had ICAs, and in childhood IDDM, 23.5\% had ICAs, despite having a similar prevalence of positive anti-thyroid autoantibodies $[8,9]$. A low level of T-cell activation cellular markers has been observed for recent-onset IDDM patients [10]. Other Asian groups, especially Koreans, also showed low frequencies of GADab and ICAs in diabetes $[11,12]$. To establish the importance of an autoimmune pathogenesis in Chinese diabetes patients, we have determined the frequency of GADab and 
its relation with ICA status, in a large group of IDDM and NIDDM patients.

\section{Subjects and methods}

Patients. Subjects were recruited from the Diabetes Clinic at our tertiary referral hospital. Venous blood was obtained in the morning by venepuncture, left to clot at $4^{\circ} \mathrm{C}$ and the serum immediately separated and stored at $-70^{\circ} \mathrm{C}$. We studied 134 patients with IDDM (51 males, 83 females) and 168 patients with NIDDM (97 males, 71 females).

We used World Health Organisation criteria for diagnosis of IDDM and NIDDM [13]. Patients with IDDM are diagnosed on the basis of classical presentation of acute abrupt symptoms and (i) with diabetic ketoacidosis at diagnosis or (ii) with the patient requiring insulin treatment at diagnosis, and continuously for 1 year. Patients who did not fall into either of these two criteria were classified as having NIDDM. Those patients who could not be assigned clearly as IDDM or NIDDM were not included in the data analyses. Less than $7 \%(22 / 324)$ of our study cohort belongs to this 'intermediate group'.

Measurement of C-peptide. Serum C-peptide levels were measured by a double antibody radioimmunoassay (Diagnostic Products Corporation, Los Angeles, Calif., USA). Serum samples $(25 \mu \mathrm{l})$ were incubated with competing ${ }^{125}$ I-labelled Cpeptide and antiserum for $4 \mathrm{~h}$ at room temperature. The separation of bound from free was achieved by a polyethyleneglycol (PEG)-accelerated double antibody method. Precipitated antibody-bound fraction was then counted and the patient sample concentrations read from a calibration curve. The test has a detection limit of $0.07 \mathrm{nmol} / \mathrm{l}$.

Detection of cytoplasmic ICA. Islet cell antibodies were detected by the indirect immunofluorescence technique as described previously [14], using unfixed cryostat sections. The same tissue was used for all determinations. The assay has a sensitivity of 5 Juvenile Diabetes Foundation Units (JDF-U) with the results reported here as positive ( $>5 \mathrm{JDF}-\mathrm{U}$ ) or negative.

Detection of antibodies to GAD. Antibodies to GAD were measured by ELISA using the capture antibody method. Microplates (Maxisorp immunoplates; Nunc A/S, Roskilde, Denmark) were first coated with $50 \mu \mathrm{l} \mathrm{GAD}-1$ monoclonal antibody (Chemicon Inc., Tumecula, Calif., USA), diluted 1:2000 in $0.1 \mathrm{~mol} / \mathrm{l}$ bicarbonate buffer $\mathrm{pH} 9.6$, overnight at $4^{\circ} \mathrm{C}$. The assay wells were drained and non-specific binding sites blocked with $100 \mu \mathrm{l} 2 \%$ non-fat milk (NFM)/phosphate buffered saline (PBS) for $2 \mathrm{~h}$ at $37^{\circ} \mathrm{C}$. After washing with PBS/ Tween 20 three times, $50 \mu \mathrm{l}$ rat brain homogenate was added to alternate duplicate wells and left to incubate for $2 \mathrm{~h}$ at $37^{\circ} \mathrm{C}$ with constant shaking. Following washing, $50 \mu$ ldiluted serum (1:50 in NFM/PBS) was added to the quadruplicate wells (with/without rat brain homogenate coating) for a further $2 \mathrm{~h}$ incubation at $37^{\circ} \mathrm{C}$ with constant shaking. Horseradish peroxidase conjugated rabbit anti-human immunoglobulins (50 $\mu \mathrm{l}$, diluted $1 / 2000$ in NFM/PBS; DAKO A/S, Glostrup, Denmark) was then added for another $2 \mathrm{~h}$ at $37^{\circ} \mathrm{C}$ with shaking. After washing, the reaction was developed with $50 \mu \mathrm{l}$ of substrate $(2 \mathrm{mmol} / \mathrm{l}$ ABTS, 2,2'-azino-di-[3-ethylbenzthiazoline sulfonate(6)] in citrate phosphate buffer $\mathrm{pH}$ 5.0; Boehringer Mannheim GmbH, Mannheim, Germany) for $30 \mathrm{~min}$ at $37^{\circ} \mathrm{C}$ with shaking. The optical density was read in a Dynatech MR700 automated plate reader (Burlington, Mass., USA) at
Table 1. Clinical characteristics of IDDM and NIDDM patients

\begin{tabular}{lll}
\hline & $\begin{array}{l}\text { IDDM } \\
(n=134)\end{array}$ & $\begin{array}{l}\text { NIDDM } \\
(n=168)\end{array}$ \\
\hline Male/female $(n)$ & $51 / 83$ & $97 / 71$ \\
Age at testing (years) & $22.1 \pm 12.9$ & $40.6 \pm 15.3^{\mathrm{b}}$ \\
Age at diagnosis (years) & $17.6 \pm 12.6$ & $38.4 \pm 15.3^{\mathrm{b}}$ \\
Duration of diabetes (years) & $4.6 \pm 6.6$ & $2.3 \pm 4.4^{\mathrm{a}}$ \\
Body mass index $\left(\mathrm{kg} / \mathrm{m}^{2}\right)$ & $19.2 \pm 3.9$ & $24.4 \pm 4.0^{\mathrm{b}}$ \\
Ketoacidosis at presentation $(n)$ & 48 & 0 \\
Mode of treatment & & \\
$\quad$ Insulin $(n)$ & 134 & 32 \\
$\quad$ Oral agent $(n)$ & 0 & 80 \\
Diet alone $(n)$ & 0 & 56 \\
\hline
\end{tabular}

Data are given as mean $\pm \mathrm{SD}$

${ }^{\mathrm{a}} p<0.001 ;{ }^{\mathrm{b}} p<10^{-6}$

$410 \mathrm{~nm}$ with $630 \mathrm{~nm}$ as reference. The difference in the mean optical density obtained in duplicate assay wells, with and without homogenate-coating, was calculated and expressed in relative units $\left(\times 10^{-3} \mathrm{OD}\right)$. The cutoff level $(2 \mathrm{SD})$ was determined with 52 healthy subjects: more than 10 relative units (RU) was considered positive for GAD antibodies. Results are reported here as positive ( $>10 \mathrm{RU}$ ) or negative. This assay procedure achieved $100 \%$ specificity and $75 \%$ sensitivity at the first GADab proficiency programme.

Statistical analysis. Data were analysed by SPSS/PC + software (SPSS Inc., Chicago, Ill., USA). The significance of differences between observations was assessed using the chi-square test or Fisher's exact probability test where appropriate. Mean values differences were assessed by the Student's $t$-test.

\section{Results}

Clinical characteristics in patients with IDDM and NIDDM, are described in Table 1 . The mean ages of IDDM and NIDDM patients tested were 22.1 and 40.6 years, and duration of diabetes 4.6 and 2.3 years, respectively. The IDDM patients had significantly lower mean BMI $\left(19.2 \pm 3.9 \mathrm{~kg} / \mathrm{m}^{2}\right)$ compared to the $\operatorname{NIDDM}\left(24.4 \pm 4.0 \mathrm{~kg} / \mathrm{m}^{2}\right)$. Only 7 of 134 IDDM patients were obese with BMI $25 \mathrm{~kg} / \mathrm{m}^{2}$ or more, their mean age at onset was $18.8 \pm 5.3$ years and 5 patients had age-onset 20 years or less. Forty-eight patients with IDDM had a history of ketoacidosis (DKA) at presentation and none of the patients with NIDDM had DKA. All patients with IDDM were on insulin treatment since diagnosis and remained on this modality continuously with no patients reverting to diet or oral agents. Thirty-two of the 168 patients with NIDDM were insulin requiring because of secondary drug failure, while the rest were treated with diet alone or oral hypoglycaemic agents at time of study.

Seventy $(52.2 \%)$ and $118(70.2 \%)$ patients with IDDM and NIDDM respectively, had a short duration diabetes ( $<1$ year), while the remaining 64 
Table 2. Prevalence of GADab and ICAs in IDDM and NIDDM patients according to youth or adult-onset and duration of diabetes

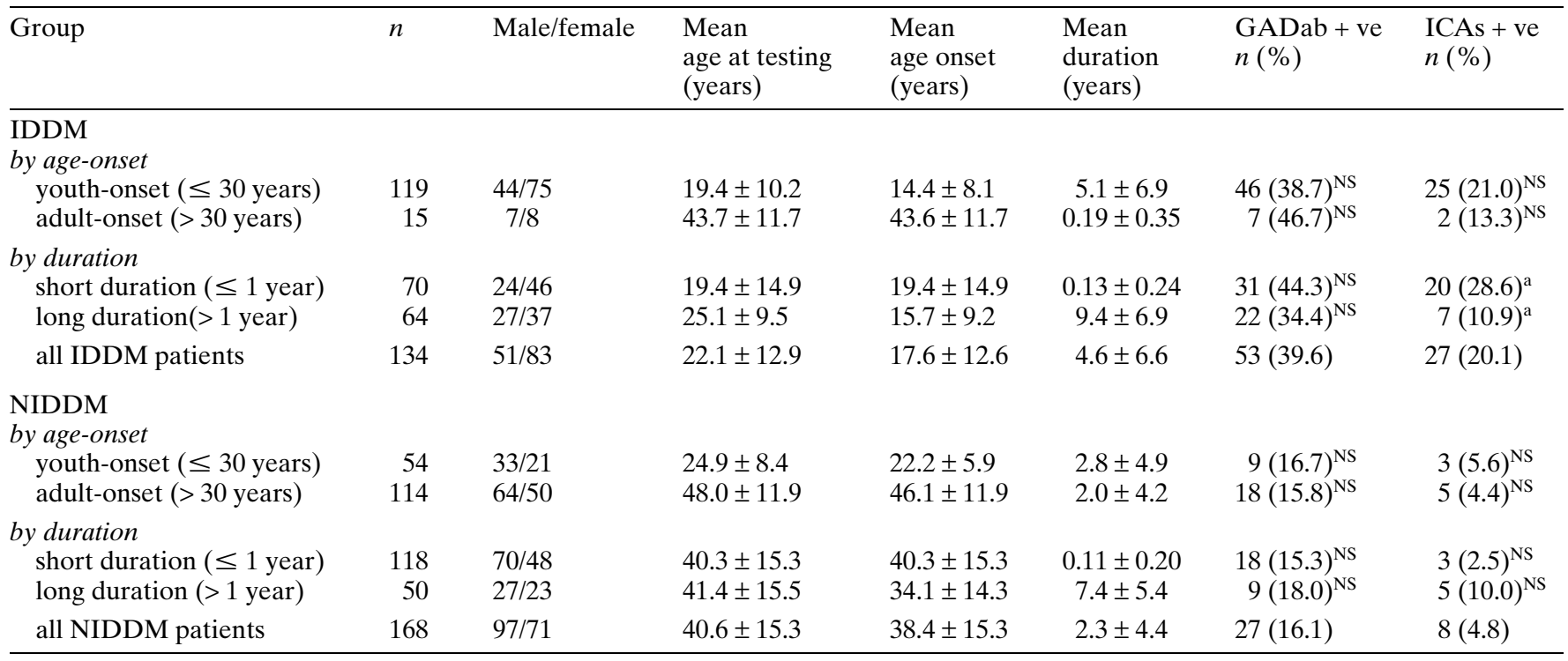

Data given as mean $\pm \mathrm{SD}$; percent given in parentheses

NS, Not significant; ${ }^{a} p<0.05$ for youth-onset vs adult-onset and short vs long duration

(47.8\%) IDDM and 50 (29.8\%) NIDDM patients had longer duration ( $>1$ year) of diabetes. One hundred and nineteen $(88.8 \%)$ of IDDM patients had youth-onset ( $\leq 30$ years), and $15(11.2 \%$ ) had adultonset ( $>30$ years) diabetes. For the NIDDM patients, these distributions were $54(32.1 \%)$ and 114 $(67.9 \%)$, respectively.

Analysis of autoantibodies according to youth or adult-onset and duration of diabetes is shown in Table 2 .

Autoantibodies in IDDM. GADab were detected in 53 of $134(39.6 \%)$ patients with IDDM. The frequency of positive GADab was not influenced by whether patients had youth-onset IDDM (46/119, 38.7\%) or adult-onset IDDM $(7 / 15,46.7 \%)$, or by whether diabetes was of short $(31 / 70,44.3 \%)$ or longer $(22 / 64$, $34.4 \%$ ) duration.

GADab was not associated with a history of DKA, being detected in $43.8 \%$ of those patients with DKA and $37.2 \%$ without DKA, which was not significantly different. This lack of association with DKA was also found when results were analysed in those patients with younger age at onset ( $\leq 20$ years) of IDDM.

Females $(39 / 83,47.0 \%)$ had a higher GADab positivity rate compared to males (14/51, $27.5 \%$; $p=0.019)$. The mean age at testing for the females was not different from males $(20.7 \pm 12.8$ vs $24.0 \pm 7.7$ years, $p=0.370$ ).

Compared to GADab, ICA was detected in a lower $(27 / 134,20.1 \%)$ proportion of IDDM patients. Prevalence of ICAs was not different in patients with youth $(25 / 119,21 \%)$ or adult-onset IDDM $(2 / 15$, $13.3 \%)$. Frequency of ICAs was however associated with duration of diabetes, being higher in those with short duration $(20 / 70,28.6 \%)$ compared to those with longer duration $(7 / 64,10.9 \%)$ of diabetes $(p=0.039)$. There was no influence of gender on frequency of ICAs, being not different in males $(8 / 51$, $15.7 \%$ ) compared to females $(19 / 83,22.9 \%)$.

Sixty-three $(47.0 \%)$ patients were seropositive for either GADab or ICAs, while $17(12.7 \%)$ patients had both antibodies. Thus a high proportion (71/134, $53 \%$ ) of IDDM patients were negative for both of these autoimmune markers.

Autoantibodies in NIDDM. GADab were detected in 27 of $168(16.1 \%)$ and ICAs in 8 of $168(4.8 \%)$ of patients with NIDDM. Prevalence rates for GADab were not related to whether NIDDM was of youth $(9 / 54,16.7 \%)$ or adult onset $(18 / 114,15.8 \%)$, or with short $(18 / 118,15.3 \%)$ or long $(9 / 50,18.0 \%)$ duration of diabetes. These observations were also shown with the prevalence rates for ICAs: youth onset $(3 / 54,5.6 \%)$, adult onset $(5 / 114,4.4 \%)$, short duration $(3 / 118,2.5 \%)$ and long duration diabetes $(5 / 50,10.0 \%)$. Prevalence rates for GADab and ICAs were also not different in males (GADab: 17/ 97, $17.5 \%$; ICAs: 4/97, 4.1\%) compared to females (GADab: 10/71, 14.1\%; ICAs: 1/71, $1.4 \%$ ). Thirty $(17.9 \%)$ patients were seropositive for either GADab or ICAs, and only $4(2.4 \%)$ for both antibodies.

Table 3 compares the clinical characteristics of IDDM and NIDDM patients who were GADab positive or negative. There was no difference in ageonset, duration of diabetes, body mass index and fasting C-peptide levels in patients who were GADab 
Table 3. Clinical characteristics of IDDM and NIDDM patients with/without GAD antibodies

\begin{tabular}{|c|c|c|c|c|}
\hline & \multicolumn{2}{|l|}{$\begin{array}{l}\text { IDDM } \\
(n=134)\end{array}$} & \multicolumn{2}{|l|}{$\begin{array}{l}\text { NIDDM } \\
(n=168)\end{array}$} \\
\hline & $\begin{array}{l}\text { GADAb+ } \\
n=53\end{array}$ & $\begin{array}{l}\text { GADAb- } \\
n=81\end{array}$ & $\begin{array}{l}\text { GADAb+ } \\
n=27\end{array}$ & $\begin{array}{l}\text { GADAb- } \\
n=141\end{array}$ \\
\hline $\begin{array}{l}\text { Age onset (years) } \\
\text { for males } \\
\text { for females }\end{array}$ & $\begin{array}{l}18.1 \pm 11.5 \\
18.9 \pm 10.5(n=14) \\
17.8 \pm 11.9(n=39)\end{array}$ & $\begin{array}{l}17.3 \pm 13.3 \\
17.7 \pm 14.9(n=37) \\
17.7 \pm 12.0(n=44)\end{array}$ & $\begin{array}{l}39.3 \pm 16.5 \\
39.5 \pm 13.4(n=17) \\
39.0 \pm 21.6(n=10)\end{array}$ & $\begin{array}{l}38.3 \pm 15.1 \\
34.7 \pm 13.0(n=80) \\
42.9 \pm 16.3(n=61)\end{array}$ \\
\hline $\operatorname{BMI}\left(\mathrm{kg} / \mathrm{m}^{2}\right)$ & $18.1 \pm 3.3$ & $19.9 \pm 4.1$ & $23.2 \pm 4.0$ & $24.6 \pm 4.0$ \\
\hline Fasting C-peptide $(\mathrm{nmol} / \mathrm{l})^{\mathrm{a}}$ & $\begin{array}{l}0.20 \pm 0.17 \\
(n=36)\end{array}$ & $\begin{array}{l}0.30 \pm 0.28 \\
(n=50)\end{array}$ & $\begin{array}{l}0.62 \pm 0.30 \\
(n=20)\end{array}$ & $\begin{array}{l}0.69 \pm 0.32 \\
(n=105)\end{array}$ \\
\hline Ketoacidosis at presentation & $21(43.8 \%)$ & $27(33.3 \%)$ & 0 & 0 \\
\hline Insulin treatment & $53(100 \%)$ & $81(100 \%)$ & $6(22.2 \%)$ & $26(18.4 \%)$ \\
\hline
\end{tabular}

Data given as mean \pm SD

${ }^{\text {a }}$ C-peptide levels from fasting specimens only available for a subgroup of patients

positive or negative, in both the IDDM and NIDDM patients.

When results were further analysed in which distinction between IDDM and NIDDM was removed, GADab was detected in $39(35.5 \%)$ of 110 patients with younger age at onset ( $\leq 20$ years), and 41 $(21.4 \%)$ of 192 patients with older age at onset ( $>20$ years) diabetes. In both groups of patients, GADab positivity was found to be associated with lower fasting C-peptide and lower BMI. This association can however be attributed to the observation that in the GADab-positive group, there were proportionately more patients with IDDM than NIDDM classified based on our clinical criteria, both in the younger age at onset $(p=0.04)$ and older age at onset $(p=0.001)$ patients.

GADab titre in NIDDM was similar to IDDM $(31.3 \pm 29.4$ vs $42.6 \pm 41.1$ relative units). Six of 27 (22.2\%) GADab-positive NIDDM patients required insulin treatment for glycaemic control compared to 26 of $141(18.9 \%)$ GADab-negative NIDDM patients, which was not statistically significant.

\section{Discussion}

Antibodies to glutamate decarboxylase were positive in $40 \%$ of our cohort of IDDM patients. This figure for GADab positivity is lower compared to European and North American figures. In Caucasians, GADab are found in $60-90 \%$ of recent-onset IDDM patients [1-4]. However, our figure for Chinese IDDM patients is consistent with a generally lower prevalence of IDDM-associated autoantibodies in Asians. Studies with small patient cohorts showed GADab prevalence rates of only 5-29\% in Japanese, Koreans, Thais and Chinese residents of Hong Kong [15, 16]. These observations were subsequently repeated by Tuomi et al. [12]. More recently, Rattarasarn et al.
[17] showed that the prevalence of GADab in 39 Thai IDDM patients was $48.7 \%$, being slightly lower $(35.7 \%)$ in those of young-onset IDDM. In Japanese, high rates similar to the Caucasians for GADab were reported [18, 19]. However in a multicentre study, Tsuruoka et al. [20] found a GADab positivity rate of $35.4 \%$ in 921 Japanese IDDM patients studied, and among those with newly diagnosed diabetes, $50.3 \%$ of the patients had detectable GADab.

Our study showed similar frequencies of GADab in patients with recent-onset IDDM (44.3\%) compared with those with longer duration of diabetes $(34.4 \%)$. This would support the view that GADab declines slowly and persists in the circulation for years, unlike ICAs. Duration of IDDM was also observed by Myers et al. [21] to have little effect on the frequency of GADab. Vandewalle et al. [22] found GADab in IDDM patients of older (20-40 years) age-onset diabetes were higher $(19 / 45,42.2 \%)$ than in those of younger age-onset ( $\leq 20$ years) patients $(31 / 82,37.8 \%)$. Our study showed that GADab were equally frequent in young or older-onset IDDM patients.

Chan et al. [16] reported their findings of antiGAD antibodies in a small cohort of 39 Chinese patients with IDDM, with mean \pm SD age of $37 \pm 15$ years. Our larger cohort of 134 IDDM patients studied had a younger mean age of $22.1 \pm 12.9$ years. Duration of diabetes in both studies was quite similar, i. e. $6.7 \pm 5.6$ compared to $4.6 \pm 6.6$ years respectively. The authors found a prevalence rate for GADab positivity of $23.1 \%$ and an association between antiGAD positivity with younger age, earlier age of onset and lower BMI while we did not find this association. An explanation for this discrepant finding is that Chan et al.'s IDDM patients were older compared to our cohort, and were relatively more heterogenous with regards to their clinical characteristics and the status of pancreatic beta-cell function compared to 
our IDDM patients. Ten $(25.6 \%)$ of the 39 IDDM patients were non-insulin-deficient (mean fasting Cpeptide $0.76 \mathrm{nmol} / \mathrm{l}$ ), and were older, had later age at onset and higher BMI compared to the insulin-deficient IDDM (mean fasting C-peptide $0.15 \mathrm{nmol} / \mathrm{l}$ ). It is therefore not surprising that the anti-GAD positive patients were confined to the insulin-deficient patients and none of the non-insulin-deficient patients were positive for anti-GAD. In comparison, the majority $(88.8 \%)$ of our IDDM patients had young-onset (age $\leq 30$ years) IDDM, while only a small proportion had adult-onset IDDM, and fasting C-peptide in these two sub-groups was not different $(0.27$ vs $0.22 \mathrm{nmol} / \mathrm{l})$.

Our study also suggests that GADab in IDDM may be gender-related being more frequent in females than males. This association has also been shown by Schmidli et al. [23] with results showing that post-pubertal females with at-risk and clinical IDDM, compared to males, had an association with GADab. This indicates that GAD autoantibody response may be operating differently at different ages, and may also be gender related [24].

Prevalence of ICAs was detected in only $20 \%$ of our IDDM patients. We did not find an association between ICAs and GADab, in contrast to observations reported [23, 25].

For NIDDM patients, we found prevalence rates for GADab of $16.1 \%$ and ICAs of $4.8 \%$. In 133 recent onset Finnish NIDDM patients aged 4564 years, 9\% had GADab and 3.8\% had ICAs [7]. Among the Wanigela people of Papua New Guinea, where susceptibility to NIDDM is high, a study of 93 newly diagnosed NIDDM diabetic patients showed no evidence of GADab [26].

Studies reported that $4.3 \%$ in 680 Japanese NIDDM had GADab [20], and in a smaller cohort of 24 Thai NIDDM, $8.3 \%$ had GADab [17]. In Koreans, $1.7 \%$ of 121 recent onset NIDDM patients (mean age 57 years) had GADab [11], a figure much lower than the GADab frequency of $15.3 \%$ in our recentonset NIDDM patients.

It was suggested that GADab may identify a latent form of insulin-dependency in NIDDM patients or LADA [6, 7]. However, in our GADab-positive NIDDM, 22.2\% (6/27) required insulin treatment, compared to 26 of $141(18.4 \%)$ in the GADab-negative sub-group, which was not statistically significant. None of the patients with NIDDM had primary drug failure requiring insulin treatment. Moreover, our NIDDM GADab-positive patients had similar ageonset, sex distribution, duration and fasting C-peptide level as in NIDDM GADab-negative patients. Our finding thus suggests that seropositivity for GADab in NIDDM does not help to distinguish a subgroup who may have latent or slow-onset IDDM.

A high $(53 \%)$ proportion of Chinese IDDM patients, has no evidence of either GADab or ICAs. This suggests that differences in aetiology may exist between racial groups. It is noteworthy that in a study of about 100 Danish patients with recent-onset IDDM measured for GADab and ICAs, findings suggest that some late-onset patients (after 30 years of age), with sera negative for ICAs, may not have an autoimmune pathogenesis [4]. It is however, also possible that other autoantigens yet to be identified, may be of greater relevance in the Chinese. HLA associations in Chinese IDDM patients have been shown to be gender- and age-related, DRB $1 * 0301 / 0901$ observed mainly in females and DRB1*0301/04 in males, with an inverse relationship seen with age-atonset for both sexes [27]. HLA associations in Chinese IDDM may be different from those in Caucasians [27, 28]. For example, the frequency of DQB1*0302 (NAsp57) a high-risk allele associated with Caucasians was not increased in our patients compared to controls [27]. Decreasing influence of HLA class II susceptibility alleles with increasing age at onset also point to a less critical role for the immune system in these patients [4].

\section{References}

1. Rowley MJ, Mackay IR, Chen Q-Y, Knowles WJ, Zimmet PZ (1992) Antibodies to glutamic acid decarboxylase discriminate major types of diabetes mellitus. Diabetes 41 : $548-551$

2. Hagopian WA, Karlsen AE, Gottsater A et al. (1993) Quantitative assay using recombinant human islet glutamic acid decarboxylase (GAD65) shows that $64 \mathrm{~K}$ autoantibodies positivity at onset predicts diabetes type. J Clin Invest 91: 368-374

3. Luhder F, Woltanski KP, Mauch L et al. (1994) Detection of autoantibodies to the $65 \mathrm{kD}$ isoform of glutamate decarboxylase by radioimmunoassay. Eur J Endocrinol 130: 575-580

4. Petersen JS, Hejnaes KR, Moody A et al. (1994) Detection of GAD65 antibodies in diabetes and other autoimmune diseases using a simple radioligand assay. Diabetes 43: 459-467

5. Zimmet PZ, Tuomi T, Mackay IR et al. (1994) Latent autoimmune diabetes mellitus in adults (LADA): the role of antibodies to glutamic acid decarboxylase in diagnosis and prediction of insulin dependency. Diabet Med 11: 299-303

6. Tuomi T, Groop LF, Zimmet PZ, Rowley MJ, Knowles W, Mackay IR (1993) Antibodies to glutamic acid decarboxylase reveal latent diabetes mellitus in adults with a non-insulin-dependent onset of diabetes. Diabetes 42: 359-362

7. Niskanen LK, Tuomi T, Karjalainen J, Groop LC, Uusitupa MIJ (1995) GADAb in NIDDM. Ten-year follow-up from the diagnosis. Diabetes Care 18: 1557-1565

8. Thai AC, Ng WY, Lui KF, Cheah JS (1994) Prevalence of islet cell antibodies in Chinese patients with recent-onset insulin-dependent diabetes mellitus. In: Min HK, Lee HK, Kaneko T, Baba S, Turtle JR (eds) Diabetes mellitus in Western Pacific Region. Proceedings of International Diabetes Federation Western Pacific Region Congress 1993, Seoul, South Korea. Korea Medical Publishing Co., Seoul, pp 61-64 
9. Thai AC, Ng WY, Lui KF, Cheah JS (1995) Islet cell and thyroid autoimmunity in Chinese patients with insulin-dependent diabetes mellitus. Diabetes Care 18: 586-587

10. Ng WY, Thai AC, Lui KF, Yeo PPB, Cheah JS (1995) Soluble markers of T-cell activation and serum cytokines in type I (insulin-dependent) diabetes mellitus. Intl Arch Allergy Immunol 108: 39-42

11. Park YS, Lee HK, Koh C-S et al. (1996) The low prevalence of immunogenetic markers in Korean adult-onset IDDM patients. Diabetes Care 19: 241-245

12. Tuomi T, Zimmet P, Rowley M (1995) Differing frequency of autoantibodies to glutamic acid decarboxylase among Koreans, Thais, and Australians with diabetes mellitus. Clin Immunol Immunopathol 74: 202-206

13. World Health Organization (1985) Diabetes mellitus: report of a WHO study group. Geneva, World Health Organization, Technical Report Series no. 727

14. Ng WY, Thai AC, Lui KF, Yeo PPB, Cheah JS (1993) Nonrestricted immunoglobulin-G subclass islet cell antibodies in Chinese. Autoimmunity 15: 305-309

15. Zimmet PZ, Rowley MJ, Mackay IR (1993) The ethnic distribution of antibodies to glutamic acid decarboxylase: presence and levels in insulin-dependent diabetes mellitus in Europid and Asian subjects. J Diab Compl 7: 1-7

16. Chan JCN, Yeung VTF, Chow CC et al. (1996) Pancreatic $\beta$ cell function and antibodies to glutamic acid decarboxylase (anti-GAD) in Chinese patients with clinical diagnosis of insulin-dependent diabetes mellitus. Diabetes Res Clin Pract 32: 27-34

17. Rattarasarn C, Aguilar-Diosdado M, Soonthornpun S, Patarakijvanich N, Jaruratanasirikul S (1996) GAD antibodies in IDDM in Thailand. Diabetes Care 19: 674-675

18. Akasawa S, Kawasaki E, Yano M, Abiru N, Yamaguchi Y, Nagataki S (1994) Autoantibodies to glutamic acid decarboxylase (GAD), 64,000-Mr islet cell protein (64 K) antibodies and islet cell antibodies (ICA) in insulin-dependent diabetes mellitus with and without autoimmune disease in Japan. Diabetes Res Clin Pract 24 [Suppl]:S89-S93

19. Yano M, Moriuchi R, Kawasaki E (1995) Autoantibodies against glutamic acid decarboxylase 65 in Japanese patients with insulin-dependent diabetes mellitus (IDDM). J Autoimmunity 8: 83-96
20. Tsuruoka A, Matsuba I, Toyota T, Isshiki G, Nagataki S, Ikeda Y (1995) Antibodies to GAD in Japanese diabetic patients: a multicenter study. Diabetes Res Clin Pract 28: 191-199

21. Myers MA, Rubin DU, Rowley MJ (1995) Pancreatic islet cell cytoplasmic antibody in diabetes is represented by antibodies to islet cell antigen 512 and glutamic acid decarboxylase. Diabetes 44: 1290-1295

22. Vandewalle CL, Falorni A, Svanholm S, Lernmark A, Pipeleers DG, Gorus FK (1995) High diagnostic sensitivity of glutamate decarboxylase autoantibodies in insulin-dependent diabetes mellitus with clinical onset age 20 and 40 years. The Belgian Diabetes Registry. J Clin Endocrinol Metab 80: 846-851

23. Schmidli RS, DeAzipurua HJ, Harrison LC, Colman PG (1994) Antibodies to glutamic acid decarboxylase in atrisk and clinical insulin-dependent diabetic subjects: relationship to age, sex and islet cell antibody status, and temporal profile. J Autoimmunity 7: 55-66

24. Zimmet PZ, Elliot RB, Mackay IR (1994) Autoantibodies to glutamic acid decarboxylase and insulin in islet cell antibody positive presymptomatic type 1 diabetes mellitus: frequency and segregation by age and gender. Diabet Med 11: 866-871

25. Roll U, Christie MR, Standl E, Zielger AG (1994) Associations of anti-GAD antibodies with islet cell antibodies and insulin autoantibodies in first-degree relatives of type I diabetic patients. Diabetes 43: 154-160

26. Dowse GK, Zimmet PZ, Spark RA, Mavo B, Rowley MJ, Mackay IR (1994) Lack of antibodies to glutamic acid decarboxylase in young adults of the high diabetes prevalence Wanigela people of Papua New Guinea. Diabetes Res Clin Pract 24: 195-198

27. Chan SH, Thai AC, Lin YN, Lui KF, Wee GB (1995) Influence of gender and age at onset on the HLA associations in Chinese with insulin-dependent diabetes mellitus. Human Immunol 44: 175-180

28. Penny MA, Jenkins D, Mijovic CH (1992) Susceptibility to IDDM in a Chinese population. Role of HLA class II alleles. Diabetes 41:914-919 